\title{
Towards Racial Justice: The Role of Medical-Legal Partnerships
}

Medha D. Makhlouf

Penn State Dickinson Law, mdm5849@psu.edu

Follow this and additional works at: https://ideas.dickinsonlaw.psu.edu/fac-works

Part of the Health Law and Policy Commons, Law and Race Commons, and the Medical Jurisprudence Commons

\section{Recommended Citation}

Medha D. Makhlouf, Towards Racial Justice: The Role of Medical-Legal Partnerships, 50 J. L. MED. \& ETHICS (2022). been accepted for inclusion in Faculty Scholarly Works by an authorized administrator of Dickinson Law IDEAS. For more information, please contactlja10@psu.edu. 


\title{
TOWARDS RACIAL JUSTICE: THE ROLE OF MEDICAL-LEGAL PARTNERSHIPS
}

\author{
Medha D. Makhlouf*
}

50 J.L. MED. \& ETHICS (forthcoming 2022)

\begin{abstract}
Medical-legal partnerships (MLPs) integrate knowledge and practices from law and health care in pursuit of health equity. However, the MLP movement has not reached its full potential to address racial health inequities, in part because its original framing was not explicitly race conscious. This article aims to stimulate discussion of the role of MLPs in racial justice. It calls for MLPs to name racism as a social determinant of health and to examine how racism may operate in the field. This work sets the stage for the next step: operationalizing racial justice in the MLP model, research, and practice.
\end{abstract}

\section{INTRODUCTION}

Law is one possible tool for addressing the social conditions that create and sustain racial health inequities. This article describes the potential of the medical-legal partnership (MLP) model for disrupting the systems responsible for creating and maintaining longstanding racial health inequities. It begins by briefly summarizing the relationships between racism, health, and access to justice. It then describes the development of the MLP model as a poverty-focused health equity intervention. It explains how MLPs employ legal interventions to address the effects of racism as a social determinant of health $(\mathrm{SDOH})$, but do not generally acknowledge the anti-racist nature of

\footnotetext{
* Medha D. Makhlouf, J.D., is an Assistant Professor and Director of the Medical-Legal Partnership Clinic at Penn State Dickinson Law.
} 
this work or adopt explicitly anti-racist missions to address institutional and structural racism as root causes of poor health. This "colorblind" conception of MLPs may limit their potential to reduce racial health inequities and, in fact, may inadvertently reinforce some of the structures underlying racial health inequities. The final portion of the article discusses the need for a racial justice strategy for MLPs to work effectively toward their goal of health equity.

This article is styled as a self-critique, interrogating the norms of the MLP movementnamely, the assumption that anti-poverty advocacy is racial justice advocacy-in order to understand how they may be holding the movement back from its health equity mission. ${ }^{1}$ It also seeks to inform future scholarship on MLPs by urging scholars to adopt the standards for publishing on racial health inequities proposed by Dr. Rhea W. Boyd and coauthors - in brief, to describe racism as "a fundamental cause of disease and the...root of racial health inequities." Embracing MLPs' potential to disrupt racist systems - in the conception of the model, in the scholarship evaluating MLPs' impact, and in our practice-will ensure that the movement's activities align with its mission and highlight its importance for advancing health equity.

\section{RACISM, HEALTH, AND ACCESS TO JUSTICE}

Racism at every level—interpersonal, institutional, and structural—negatively impacts health. ${ }^{3}$ For example, individual-level racism, stereotyping, and bias in the health care system can reduce the quality of care that racial minorities receive. ${ }^{4}$ Institutional racism perpetuates unequal access to material resources, including health care, through facially neutral organizational practices and policies. $^{5}$ Academics have defined structural racism in different ways; this article adopts a straightforward definition, offered by Ruqaiijah Yearby, that links structural racism and racial health disparities: "Structural racism is the way our systems (health care, education, employment, housing, and public health) are structured to advantage the majority and disadvantage racial and 
ethnic minorities. More specifically, it produces differential conditions between white populations and racial and ethnic minorities..., leading to racial health disparities." ${ }^{\prime 6}$ Systematic health differences by race and ethnicity in the United States are the fruits of structural racism, including "the way laws are written or enforced, which advances the majority, and disadvantages racial and ethnic minorities in access to opportunity and resources." "Structural racism is the root cause of racial inequities in health outcomes.

The relationship between health and access to justice runs in both directions: Lack of access to justice contributes to poor health, and poor health can create obstacles to accessing justice. Nearly any type of unmet civil legal need can constitute a barrier to good health. ${ }^{8}$ The "I-HELP" acronym is often cited to describe the legal domains in which MLPs frequently operate: Income and insurance, housing and utilities, education and employment, legal status, and personal and family stability. ${ }^{9}$ MLPs have developed screening tools to identify unmet civil legal needs within these domains, such as stopping evictions, negotiating educational accommodations, and obtaining guardianships. MLP services improve patients' material and environmental conditions, which, it is theorized, will improve their health outcomes. For example, the Penn State Dickinson Law MLP Clinic, an experiential course in which law students provide legal services to clients under the supervision of a licensed attorney and law school faculty member, primarily represents noncitizens whose immigration status constitutes a barrier to health. ${ }^{10}$ Its practice focuses on appealing wrongful denials of applications for public benefits like Medicaid, the Supplemental Nutrition Assistance Program, Temporary Assistance for Needy Families, and the Low-Income Home Energy Assistance Program. These programs promote health and well-being in qualifying lowincome households by providing income and income supports.

Finally, law is a tool that can be used to address racism at each of the three levels described 
earlier. For example, lawyers can challenge the erroneous termination of health-promoting public benefits to Black, Indigenous, Latinx, and people of color who face intersectional discrimination because they have Limited English Proficiency (LEP) or limited literacy skills. The MLP Clinic at Penn State Dickinson Law has successfully advocated for restoration of public benefits for clients who were not provided with information in a format they can understand, as required by law. On an institutional level, lawyers can help health care providers address racial health care inequity within their institutions by adapting policies and practices to ensure that LEP patients, who are primarily noncitizens of color, receive health information through a certified medical interpreter. Continuing with this example, at the structural level, they can file lawsuits challenging executive agency actions to eliminate protections for LEP individuals in health care $^{11}$ or administrative complaints alleging underenforcement of health-promoting laws. ${ }^{12}$

\section{Medical-Legal Partnership as a Poverty-Focused Health EQuity Intervention}

The MLP model is designed to foster collaboration between legal and health care professionals for the benefit of patients who have health-harming legal needs and do not have the resources to resolve them. The MLP model originated in 1993, when pediatricians at Boston Medical Center realized that they needed lawyers on their team to help their patients be healthier. ${ }^{13}$ Lawyers were helpful for "pressuring recalcitrant landlords [to fix poor housing conditions], helping families apply for food stamps and persuading insurance companies to pay for baby formula." ${ }^{14}$ MLPs have been established in at least 450 sites in 49 states and the District of Columbia, ${ }^{15}$ as well as in Canada and Australia. ${ }^{16}$ The MLP movement has entered national consciousness, as indicated by President Biden's recognition of MLPs as "innovative and evidence-based solutions for access to justice, $" 17$ and is poised to grow.

MLPs are typically described as operating on three levels to improve patients' health: resolving 
legal issues for individual patients, influencing institutional practices to better serve those patients, and advocating to eliminate systemic barriers to good health for patients with few resources. ${ }^{18}$ Health care providers are trained to identify patients' unmet, health-harming, civil legal needs and to refer those patients to the MLP. ${ }^{19}$ MLP services, like other legal aid services, are provided to patients at no cost. MLPs rely on a patchwork of funding, including financial, staffing, and resource commitments by participating health care and legal services organizations and law schools; non-profit hospital community benefit funds; Health Resources \& Services Administration enabling services funds; Legal Services Corporation funds; Interest on Lawyers Trust Account funds; legal aid fellowship programs; and philanthropy. ${ }^{20}$

MLP is a uniquely upstream/downstream, collaborative, and community-based model of legal services that is aimed at achieving health equity. In the context of MLPs, "health equity" has been defined as "an environment in which every individual has an equal opportunity to achieve and maintain good health. ${ }^{21}$ By bringing lawyers on to health care teams to address unmet legal needs at the individual patient level but also supporting the identification and remediation of institutional and systemic issues that create health-harming legal needs, MLPs can be both a downstream intervention at the point of health care delivery and an upstream, population health intervention. ${ }^{22}$ For example, MLPs can both ensure that housing codes on the books are properly enforced and advocate for better protections from health hazards for residents of subsidized housing. ${ }^{23}$ MLPs are collaborative in that they seek to capture the synergy that results from interactions of legal and health care professionals who are committed to reducing health disparities. ${ }^{24}$ When these relationships are not intentionally cultivated, efforts to address $\mathrm{SDOH}$ are more likely to be siloed and less effective. Co-locating legal services at the health care provider site, a feature of MLPs, brings legal services into the community in a way that providing services from a stand-alone office 
does not: It has the potential to reach clients who would not have otherwise sought out legal services. $^{25}$

The mechanisms by which MLP has been theorized to reduce racial health inequities are identifying discriminatory practices through individual-level work; ${ }^{26}$ intervening to remediate health-harming legal issues that disproportionately affect Black, Indigenous, Latinx, and people of color; and changing laws or the unjust application of laws that maintain racial health inequities. ${ }^{27}$ Disparate access to the building blocks of health and wellness - such as health care, adequate nutrition, safe and secure housing, appropriate education, and protection from interpersonal violence-is linked to racial health inequities. ${ }^{28}$ MLPs employ legal interventions to address these "health-harming legal and social challenges," ${ }^{29}$ such as by expanding access to financial resources, thus creating the opportunity to reduce poverty-related barriers to health for clients who are Black, Indigenous, Latinx, people of color, and other historically marginalized populations. At scale, MLPs could have an impact on racial health inequities at the community or population level. ${ }^{30}$ However, the evidence base to support these claims is not yet established. ${ }^{31}$

Even though Black, Indigenous, and Latinx people are disproportionately affected by the poverty-related issues that MLPs address, it is not yet commonplace for MLPs to describe their approach as a racial justice intervention. ${ }^{32}$ Rather, since its inception, MLP has been characterized as a legal intervention to improve the health of people affected by poverty-related issues. ${ }^{33}$ When the term "health disparities" is used in the MLP literature, it is not always clear whether authors are referring to disparities by income, race, or the intersection of the two. ${ }^{34}$ Similarly, while there certainly are MLPs that would characterize their work as anti-racist, it is not always apparent from their program descriptions or missions, which use phrases such as "health-harming social conditions" or "social determinants of health" without explicitly naming racism. ${ }^{35}$ More recently, 
some participants in academic MLPs have sought to align the MLP model with the health justice framework, which emphasizes the importance of confronting racial injustice. ${ }^{36}$ However, this conception is still emerging and may not be widely known or accepted among researchers ${ }^{37}$ or MLP practitioners on the ground. ${ }^{38}$

One barrier to recasting MLP as a racial justice intervention is its original framing through a singular poverty lens. This perspective was shaped by the institutions from which the MLP movement arose: legal services and health care. ${ }^{39}$ The attorneys involved with the development of MLP were from the legal services sector, which exists to provide access to justice to low-income people. ${ }^{40}$ Like many public interest attorneys,${ }^{41}$ the early MLP attorneys likely assumed that their anti-poverty efforts constituted anti-racist efforts, particularly when the majority of those served were people of color. ${ }^{42}$ In addition, legal services attorneys typically ground their anti-poverty work in social justice, and therefore may not have felt the need to explicate their approach as civil rights or even anti-racism by proxy. ${ }^{43}$ At times, MLP attorneys may have chosen strategically to use poverty-related proxies for structural racism in describing their missions in order to solidify partnerships with certain health care partners that may not have felt comfortable adopting the language of racial justice. ${ }^{44}$ When the National Center for Medical-Legal Partnership (NCMLP) was established in 2006, its mission aligned with these perspectives, focusing on linking the legal and health care professions to address poverty-related legal issues. ${ }^{45}$ Just as there is a racial reckoning happening in many of the institutions already participating in MLPs, ${ }^{46}$ the time is right for MLPs to join these efforts if they have not already. Many MLPs have begun to recognize the limitations of the singular poverty lens for addressing racial health inequities, as described in Part III, and are thinking through ways to expand their mission and their capability to address structural racism. ${ }^{47}$ The perspective of MLPs, which sit at the nexus of health care and legal services, is 
unique, and it is up to MLP practitioners to ensure that this value is recognized.

\section{THE NEED FOR A RACIAL JUSTICE STRATEGY FOR MLPS}

Although the explicit racial barriers in laws and institutional policies that created racial stratification in U.S. society are mostly no longer in effect, present-day laws and policies continue to uphold forms of subordination that limit opportunities to be healthy. Often, these laws and policies are related to poverty, such as exclusionary zoning policies that prohibit affordable housing development in neighborhoods that would facilitate access to economic and recreational opportunities, high-quality education and health care, and healthy food options. Poverty-related laws implicate race because "racism across policies, institutions, and systems has resulted in the fact that people of color are more likely to be poor than their white counterparts." ${ }^{48}$ Recent data on poverty displays a predictable racial hierarchy: In 2019, the poverty rate for American Indians/Alaska Natives was estimated at 24.2\%, compared with $21.2 \%$ for Black people, $17.2 \%$ for Hispanic people of any race, 9.7\% for Asians/Native Hawaiians and Pacific Islanders, and $9.0 \%$ for non-Hispanic White people. ${ }^{49}$ In other words, laws and policies that appear to reinforce stratification by income alone are also maintaining racial stratification because of the ways in which poverty and racial discrimination intersect to compound disadvantage. These forms of subordination operate independently and jointly to create and perpetuate health inequities.

Viewing the mission and practice of MLPs through an intersectional racial justice lens rather than a singular poverty lens may improve their ability to work effectively for health equity. A racial justice approach incentivizes organizations to identify racial injustice, analyze how racism is operating within their organization and in their policy spaces, and take corrective action. If, on the other hand, MLPs view their clientele and available interventions through a singular poverty lens, they risk reinforcing racial stratification. ${ }^{50}$ For example, an MLP may provide excellent 
advocacy for students to receive appropriate Individual Education Plans, but consistently obtain fewer services for Black students as compared with white students because Black students are more likely to attend underfunded schools as a result of residential segregation. The MLP is thereby compounding existing racial stratification in access to high-quality education. Dina Shek described this problem in an article describing why and how MLP Hawai'i centers racial justice and community lawyering in its mission and practice: "[U]nequal access [to good education, employment, housing, and food] is a crucial aspect of racial justice. But ending a health justice approach at the promise of 'access' without also prioritizing racial justice and civic engagement risks maintaining structural inequalities and community powerlessness. ${ }^{.51}$ Along these lines, legal scholars developing the health justice framework have described how racial disparities in access to the material and environmental conditions that support health derive from laws and policies that enact racial subordination. ${ }^{52}$ They urge those working for health equity to directly address laws and policies maintaining structural racism. ${ }^{53}$ In the example described here, that could mean advocating for equitable funding and access to high-quality educational services in the public school system.

If MLPs are committed to addressing the root causes of health inequities, the first step, if they have not already done so, is to explicitly acknowledge structural racism as a driver of poor health. ${ }^{54}$ If, upon reflection, MLP practitioners find that they have "presumed intersectionality" rather than adopting an explicitly race-conscious perspective, they might begin the process of moving toward a racial justice approach through self-education on the academic literature on structural racism as an important determinant of racial health inequities. The literature cited in Part I of this article may be a good place to start. To understand what MLP participants know and believe about the relationships among racism, health, and poverty on a wide scale, it would be advisable for the 
entire field to engage in self-examination through a survey on these topics. The results would provide information on how these views influence our work and help to chart a path forward for the MLP movement.

Not naming structural racism as a determinant of health risks creating an environment in which the effects of racialization on the population served is overlooked. It unnecessarily "restrict[s] the vocabulary for describing problems, limiting the availability of data for studying racial problems and discarding the tools with which to remedy them. ${ }^{, 55}$ It provides an incomplete picture of the significance of racism as a driver of health inequities. ${ }^{56}$ It can even make such discussions taboo. While some may raise concerns about focusing on racial health disparities because of potential stigmatization of racial and ethnic minorities, such concerns are short-sighted: The COVID-19 pandemic put a spotlight on racial health disparities, and it is better to preempt potential stigmatization by providing context for the appallingly disproportionate rates of morbidity and mortality in certain minority communities. ${ }^{57}$ Similarly, failing to explain the reasons why many organizations, including MLPs, that aim to serve poor people primarily serve people of color creates a risk that people (MLP practitioners, clients, researchers, the general public) will provide their own explanations based on discredited theories about biological race ${ }^{58}$ - theories that may have arose in part from overt exploitation or racialized stereotypes. ${ }^{59}$ In the United States, illness, injury, and financial struggles are often attributed to personal failures rather than structural failures. ${ }^{60}$ This ideology of personal responsibility underlies the tendency to blame patients' behaviors or biology for problems that originate in racist policies, institutions, and systems, making it harder to direct resources to addressing the underlying causes of racial health inequities. ${ }^{61}$ Instead, resources are allocated to individual-level behaviorist interventions, some of which may actually enhance the disparities they seek to address. ${ }^{62}$ 
Once members of the organization are confident in their understanding of structural racism's role in creating health disparities, they might engage in an internal examination of the assumptions about race that have operated and currently operate within their organizations. It is critical for every member of the organization to understand why it has framed its work through a singular poverty lens, and the importance of using intersectional lenses that account for the compounded disadvantage that structural racism, among other forms of discrimination, imposes. The discussion in Part II of the history of the MLP movement, as well as the legal and medical professions from which it arose, is a place to start; however, it may be more impactful for individual MLPs to investigate their own forebearer institutions. This investigation may also serve as the basis for the MLP to develop strategies to hold their own institutions accountable for practices that create and maintain racial subordination. ${ }^{63}$ For example, an MLP could find that the racial demographics of their clients do not represent the community in which they are located because Black, Indigenous, Latinx or people of color are being referred for services at lower rates than white patients. This is a matter of racial justice because exclusion of Black, Indigenous, Latinx, or people of color from services compounds historical inequities in access to civil justice for these communities. Corrective action may include changes to or automation of the referral process to eliminate implicit bias in the referral system, if this is determined to play a role in the problem. Intensive selfexamination of this type-especially by organizations linked to institutions that participated or participate in the subordination of minoritized groups - are more likely to achieve meaningful results from their racial justice efforts. ${ }^{64}$

\section{CONCLUSION}

This moment of racial reckoning is an ideal time to interrogate the central assumptions of the MLP field, examine their impact on its health equity mission, and take corrective action to ensure 
that our practice aligns with our values. This article summarizes information about the relationships among racism, health, and access to justice that is essential to understand before beginning this process. It also provides insights about the development of the MLP model that may inform the approaches of researchers and practitioners in the field. Finally, it makes the case for more widespread adoption of racial justice strategies in MLPs. To move closer to that goal, researchers and practitioners should assess potential frameworks for theorizing racial justice approaches in MLPs and publicize examples from the field of how to operationalize racial justice in the model, in our research, and in practice.

\section{ENDNOTES}

1. See C.L. Ford \& C.O. Airhihenbuwa, "The Public Health Critical Race Methodology: Praxis for Antiracism Research," Social Science \& Medicine 71 (2010): 1390-1398, at 1396.

2. Id.

3. See, e.g., C.P. Jones, "Confronting Institutionalized Racism," Phylon 7 (2003), at 7; American Public Health Association, "Research and Intervention on Racism as a Fundamental Cause of Ethnic Disparities in Health,” American Journal of Public Health 91, no. 3 (2001): 515-516; D.R. Williams et al., "The Concept of Race and Health Status in America," Public Health Reports 109, no. 1 (1994): 26-41. Some empirical studies have begun to investigate and explain the relationship between structural racism and poor health, but there is a need for more research in this area to

expand the evidence base. See Z. Bailey et al., "Structural Racism and Health Inequities in the USA: Evidence and Interventions," Lancet 389 (2017): 1453-1463, at 1457.

4. See Jones, supra note 3 at 8 .

5. See E. Benfer et al., "Health Justice Strategies to Combat the Pandemic: Eliminating Discrimination, Poverty, and Health Disparities During and After COVID-19," Yale Journal of 
Health Policy, Law, and Ethics 3 (2020): 122-171, at 130.

6. R. Yearby, "Structural Racism and Health Disparities: Reconfiguring the Social Determinants of Health Framework to Include the Root Cause," Journal of Law, Medicine \& Ethics 48 (2020): $518-26$, at 518 .

7. R. Yearby \& S. Mohapatra, "Law, Structural Racism, and the COVID-19 Pandemic," Journal of Law \& the Biosciences 7, no. 1 (2020): 1-20, at 3-4.

8. B. Zuckerman et al., "Medical-Legal Partnerships: Transforming Health Care," The Lancet 372 (2008): 1615-1617, at 1616.

9. M. Regenstein et al., "Addressing Social Determinants of Health Through Medical-Legal Partnerships," Health Affairs 37, no. 3 (2018): 378-385, at 380.

10. Medical-Legal Partnership Clinic, Penn State Dickinson Law, at https://dickinsonlaw.psu.edu/medical-legal-partnership-clinic (last visited June 28, 2021).

11. See, e.g., Complaint for Declaratory and Injunctive Relief, Chinatown Service Center v. HHS (D.D.C. 2021), (No. 1:2021 cv0031) (challenging a regulation that rolled back protections against discrimination in health care access, including language access provisions, during the COVID-19 pandemic).

12. See, e.g., National Health Law Program, Administrative Complaint, Discriminatory Provision of COVID-19 Services to Persons with Limited English Proficiency (Apr. 30, 2021).

13. See C. Goldberg, "Boston Medical Center Turns to Lawyers for a Cure," New York Times, $\begin{array}{lllll}\text { May } & 16, & 2001, & \text { at } & \text { A20 }\end{array}$ https:/timesmachine.nytimes.com/timesmachine/2001/05/16/339733.html?pageNumber=18 (last visited June 28, 2021). Medical-legal collaborations to improve patients' health—including joint advocacy by attorneys on staff at the Delta Health Center in Mound Bayou, Mississippi, in the 
1960s, and Whitman-Walker Health in Washington, D.C., in the 1980s - existed long before this.

See J. Teitelbaum \& E. Lawton, "The Roots and Branches of the Medical-Legal Partnership Approach to Health: From Collegiality to Civil Rights to Health Equity," Yale Journal of Health Policy, Law \& Ethics 17, no. 2 (2017): 343-377, at 355. However, the MLP model developed in Boston was the one which inspired the current movement.

14. Goldberg, supra note 3, at A20.

15. Medical-Legal Partnerships Across the U.S., National Center for Medical-Legal Partnership, at https://medical-legalpartnership.org/partnerships/ (last visited June 28, 2021).

16. International Medical-Legal Partnerships, National Center for Medical-Legal Partnership, at https://medical-legalpartnership.org/partnerships/international/ (last visited June 28, 2021).

17. Joseph R. Biden Jr., Memorandum on Restoring the Department of Justice's Access-to-Justice Function and Reinvigorating the White House Legal Aid Interagency Roundtable, The White House, May 18, 2021, at https://www.whitehouse.gov/briefing-room/presidentialactions/2021/05/18/memorandum-on-restoring-the-department-of-justices-access-to-justicefunction-and-reinvigorating-the-white-house-legal-aid-interagency-roundtable/ (last visited June 28, 2021).

18. See, e.g., B. Zuckerman et al., "Why Pediatricians Need Lawyers to Keep Children Healthy," Pediatrics 114, no. 1 (2004): 224-228, at 226.

19. Id.

20. J. Trott et al., Financing Medical-Legal Partnerships: View from the Field (Apr. 2019): at 3-5. 21. J.B. Teitelbaum et al., "Striving for Health Equity through Medical, Public Health, and Legal Collaboration," Journal of Law, Medicine \& Ethics 47, no. S2 (2019): 104-107, at 106.

22. E. Tobin-Tyler \& J.B. Teitelbaum, "Medical-Legal Partnership: A Powerful Tool for Public 
Health and Health Justice," Public Health Reports 134, no. 2 (2019): 201-205, at 201.

23. See, e.g., Teitelbaum \& Lawton, supra note 3, at 369.

24. Zuckerman et al., supra note 8, at 1616.

25. Id. Less commonly, legal services providers in MLPs facilitate existing or new clients' access to integrated medical care. One example is Terra Firma, an MLP that serves unaccompanied immigrant children. Terra Firma, at terrafirma.nyc (last visited August 13, 2021).

26. See, e.g., Regenstein et al., supra note 9, at 380.

27. Teitelbaum et al., supra note21, at 105.

28. See, e.g., P.A. Braveman et al., "Health Disparities and Health Equity: The Issue is Justice," American Journal of Public Health 101, no. S1 (2011): S149-S155, at S151.

29. Teitelbaum \& Lawton, supra note 13, at 366.

30. See, e.g., Teitelbaum et al., supra note 21 , at 105 .

31. O. Martinez et al., "Bridging Health Disparity Gaps through the Use of Medical Legal Partnerships in Patient Care: A Systematic Review," Journal of Law, Medicine \& Ethics, 45 (2017): 260-273, at 261, 269. The authors note the need for more "rigorous, replicable evaluations" of the MLP model generally. Id. at 266. There is evidence that MLPs positively impact patients' health and wellbeing, housing and utility stability, and access to financial resources and concrete supports; health care systems and workforce; and policies, laws, and regulations. Caitlin Murphy, National Center for Medical-Legal Partnership, Making the Case for Medical-Legal Partnerships: An Updated Review of the Evidence, 2013-2020 (Jan. 6, 2021): at 5.

32. See, e.g., D. Bowen Matthew, The Law as Healer: How Payingfor Medical-Legal Partnerships Saves Lives and Money (Jan. 2017): at 24 ("[C]urrently, no MLP in the nation focuses on reducing health disparities by directly addressing racial and ethnic discrimination in education or any other 
social determinant of health.”). In a review of 241 MLP websites, only eighteen explicitly stated in their program mission or description an intention to serve Black, Indigenous, Latinx, or people of color (or used terminology such as "marginalized populations" that one might infer to include the forgoing communities). M.D. Makhlouf, S. Carnahan, \& P. Dhungana, MLP Mission Survey, (June 24, 2021), n.p. This review provides some information about how MLPs are framing their work, but a more thorough study is warranted.

33. See, e.g., Regenstein et al., supra note 9, at 380; Zuckerman et al., supra note 8, at 224-227. A notable exception is D. Shek, "Centering Race at the Medical-Legal Partnership in Hawai' i," University of Miami Race \& Social Justice Law Review 10 (2019): 109-46, at 112-113, 119 (describing the racial justice vision and community lawyering approach of MLP Hawai'i).

34. See, e.g., Zuckerman et al., supra note 8, at 1615-16 (stating that MLP "is emerging as a key strategy to combat health disparities," but referring to the patients served as "on low incomes" and "vulnerable," without reference to racial health inequities); Medha D. Makhlouf, interview with Ellen Lawton, Joel Teitelbaum, and Bethany Hamilton (June 7, 2021) (Ellen Lawton confirming that the foundational MLP articles and research often relied on proxies for race, racism, and even health disparities).

35. See M.D. Makhlouf, S. Carnahan, \& P. Dhungana, supra note 32 (finding that 72 of 241 MLP websites reviewed used such phrases without mentioning race, racism, people of color, or other terms connoting a race-conscious approach).

36. See E.B. Healton et al., "Training Future Health Justice Leaders-A Role for Medical-Legal Partnerships," N. Engl. J. Med. 384, no. 20 (2021): 1879-1881; S. Foster et al., "Health Justice Is Racial Justice: A Legal Action Agenda For Health Disparities," Health Affairs Blog, July 2, 2020, https://www.healthaffairs.org/do/10.1377/hblog20200701.242395/full/ (last visited June 28, 
2021); Tobin-Tyler \& Teitelbaum, supra note 22; E.A. Benfer, "Health Justice: A Framework (and Call to Action) for the Elimination of Health Inequity and Social Justice," American University Law Review 65 (2015): 275-351.

37. Martinez et al., supra note 31, at 269 (noting that "[n]ot a single study in this review considered race, ethnicity or sexuality as mediating factors impacting health outcomes.").

38. See, e.g., Bowen Matthew, supra note 32, at 24; M.D. Makhlouf, S. Carnahan, \& P. Dhungana, supra note 32.

39. This brief description of the professional cultures influencing the development of the MLP movement does not mean to ignore the role of dissenting/activist and explicitly anti-racist traditions within those fields. It will be critical to draw upon those traditions when thinking about frameworks for operationalizing racial justice in MLPs.

40. See What is the Legal Services Corporation?, at https://www.lsc.gov/ourimpact/publications/other-publications-and-reports/what-legal-services-corporation (last visited June 28, 2021).

41. See A.O. Adediran \& S. Ossei-Owusu, "The Racial Reckoning of Public Interest Law," California Law Review Online 12 (2021): 1-15, at 4.

42. Medha D. Makhlouf, supra note 34; see Adediran \& Ossei-Owusu, supra note 41 , at 4 (referring to this phenomenon as "presumed intersectionality").

43. Medha D. Makhlouf, supra note 34.

44. Id.; see B. Wispelwey \& M. Morse, "An Antiracist Agenda for Medicine," Boston Review, Mar. 17, 2021, available at http://bostonreview.net/science-nature-race/bram-wispelweymichelle-morse-antiracist-agenda-medicine.

45. Medha D. Makhlouf, supra note 34. The current and past Directors of the NCMLP describe it 
as a "big tent" organization that does not speak for all MLPs. Id. At the time of its founding, there were already approximately 75 MLPs around the country. Id. The NCMLP website states that it "leads education, research, and technical assistance efforts to help every health organization in the United States leverage legal services as a standard part of the way they respond to social needs." About the National Center for Medical-Legal Partnership, https://medicallegalpartnership.org/about-us/ (last visited June 28, 2021). The NCMLP has done laudable and groundbreaking work to this end: using the language of public health and health care to talk about poverty-related health inequities and to explain how law is a tool to address SDOH.

46. See, e.g., American Medical Association, Organizational Strategic Plan to Embed Racial Justice and Advance Health Equity, 2021-2023; National Legal Aid \& Defender Association, Racial Justice Action Plan, Oct. 2018, available at https://www.nlada.org/sites/default/files/pictures/NLADA Racial Justice Action Plan \%280ct \%202018\%29.pdf.

47. Personal communication from Emily Benfer to author (MDM) (June 23, 2021).

48. A. Plough \& G.C. Christopher, "The Role of Racial Justice in Building a Culture of Health," $\begin{array}{llllll}\text { Health } & \text { Affairs } & \text { Blog, } & \text { Sept. } & \text { 16, 2020, }\end{array}$ https://www.healthaffairs.org/do/10.1377/hblog20200914.537608/full/ (last visited June 26, 2021).

49. Poverty Rate by Race/Ethnicity, Kaiser Family Foundation, at https:/www.kff.org/other/stateindicator/poverty-rate-by-

raceethnicity/?currentTimeframe $=0 \&$ sortModel $=\% 7 \mathrm{~B} \% 22$ colId $\% 22: \% 22$ Location $\% 22, \% 22$ sort \%22:\%22asc\%22\%7D (last visited June 26, 2021).

50. See, e.g., Ford \& Airhihenbuwa, supra note Error! Bookmark not defined., at 1395. 
51. Shek, supra note 33, at 116. See also Ford \& Airhihenbuwa, supra note Error! Bookmark not defined., at 1391 (describing how, in public health research, "racial inequities generally are attributed to non-racial (e.g., socioeconomic) factors while potentially relevant racial factors (e.g., discrimination) remain largely unexamined.”).

52. Benfer et al., supra note 5, at 134-35.

53. Id. at 138 .

54. See, e.g., Shek, supra note 33, at 113.

55. Ford \& Airhihenbuwa, supra note Error! Bookmark not defined., at 1393.

56. F.M. Mitchell et al., "Health Inequities in Historical Context: A Critical Race Theory Analysis of Diabetes among African Americans and American Indians," Race and Social Problems 12 (2020): 289-299, at 295 .

57. M. Chowkwanyun \& A.L. Reed, "Racial Health Disparities and Covid-19-Caution and Context," N. Engl. J. Med. 383, no. 3 (2020): 201-203, at 203.

58. O. Obasogie et al., "Race, Law, and Health Disparities: Toward a Critical Race Intervention," Annual Review of Law \& Social Sciences 13 (2017): 313-329, at 315 (noting the endurance of biological explanations for racial differences in the public health and medical literature).

59. See R. Boyd et al., “On Racism: A New Standard For Publishing on Racial Health Inequities,” Health Affairs Blog, at https://www.healthaffairs.org/do/10.1377/hblog20200630.939347/full/ (last visited May 19, 2021); Chowkwanyun, supra note 57, at 202.

60. See Boyd, et al., supra note 59.

61. Id.

62. J.M. Metzl \& D.E. Roberts, "Structural Competency Meets Structural Racism: Race, Politics, and the Structure of Medical Knowledge, Virtual Mentor 16, no. 9 (2014): 674-690, at 682 (naming 
diagnostic criteria, dietary guidelines, and public-health safety precautions as examples).

63. Benfer et al., supra note 5.

64. See, e.g., K.J. Merchant, "Questions for the Law Firm Antiracism Alliance From a Racial

Justice Advocate," Bloomberg Law, at https://news.bloomberglaw.com/tech-and-telecomlaw/questions-for-the-law-firm-antiracism-alliance-from-a-racial-justice-advocate (last visited June 28, 2021). 